\title{
Comparison of Cardiac Output of Cricket Players before and after Step Test according to their Playing Positions
}

\author{
Lokendra Bahadur Kathayat and Ashok Kumar
}

\begin{abstract}
Aims: The purpose of this study was to compare the cardiac output of cricket players before and after step test according to their playing positions. Materials and Methods: There was one hundred fifty $(\mathrm{N}=150)$ trained male cricketers between the ages of 15 and 25 years volunteered for this study. Anthropometric rod, Weighing machine were used. Blood pressure was recorded with a digital sphygmomanometer according to the standardized protocol recommended by World Health Organization. Results: The mean age, height weight and BMI (body mass index) of batsman cricketer was $17.75 \pm 2.88$ year, $171.00 \pm 6.56 \mathrm{~cm}, 57.00 \pm 8.80 \mathrm{~kg}$ and $19.42 \pm 2.22 \mathrm{~kg} / \mathrm{m}^{2}$ respectively. The mean age, height weight and BMI (body mass index) of fast-bowler cricketer was $18.06 \pm 2.43$ year, $172.68 \pm 7.50 \mathrm{~cm}, 59.16 \pm 8.99 \mathrm{~kg}$ and $19.84 \pm 2.99 \mathrm{~kg} / \mathrm{m}^{2}$ respectively. The mean age, height weight and BMI (body mass index) of spinner cricketer was $17.88 \pm 2.93$ year, $169.40 \pm 8.94 \mathrm{~cm}$, $56.32 \pm 10.45 \mathrm{~kg}$ and $19.54 \pm 2.87 \mathrm{~kg} / \mathrm{m}^{2}$ respectively. The mean age, height weight and BMI (body mass index) of batsman/wicketkeeper cricketer was $18.08 \pm 3.47$ year, $172.75 \pm 8.30 \mathrm{~cm}, 58.67 \pm 10.34$ $\mathrm{kg}$ and $19.56 \pm 2.47 \mathrm{~kg} / \mathrm{m}^{2}$ respectively. The mean age, height weight and BMI (body mass index) of all-rounder cricketer was $17.26 \pm 1.74$ year, $170.81 \pm 7.74 \mathrm{~cm}, 56.89 \pm 10.10 \mathrm{~kg}$ and $19.42 \pm 2.71 \mathrm{~kg} / \mathrm{m}^{2}$ respectively. The mean cardiac output (at rest) of batsman, fast-bowler, spinner, batsman/wicketkeeper, all-rounder cricket players was $6.28 \pm 1.08(\mathrm{ml} / \mathrm{min}), 6.06 \pm 0.99(\mathrm{~L} / \mathrm{min})$, $6.27 \pm 1.28(\mathrm{~L} / \mathrm{min}), 6.31 \pm 1.48(\mathrm{~L} / \mathrm{min})$ and $6.07 \pm 1.01(\mathrm{~L} / \mathrm{min})$ respectively. Conclusion: It was concluded that the cardiac output was significantly increased substantially, up to 23 percent after step test than at rest of cricket players. The maximum mean cardiac output at rest was of Spinner. After step test, the maximum mean cardiac output was of all-rounder. The trained cricketers were able to increase their SBP with relatively lower heart rates. Cricketers were also having much lower resting heart rates and their heart rates reached to basal levels more quickly after step test. The DBP response between the resting and after queens step test did not differ much. This shows that regular physical training has beneficial effect on the body's cardiovascular system by making it better adapt to situations of demand like physical exercise.
\end{abstract}

\section{LokendraBahadurKathayat}

Ph.D. Scholar

Department of Sports Science

Punjabi University (Patiala) Punjab, India.

Email: lukskathayat@gmail.com

\section{Ashok Kumar}

Professor

Department of Sports Science

Punjabi University (Patiala) Punjab, India.

Email: akashokin@gmail.com
Key words: BMI, Cardiac output, Heart Rate, Stroke Volume, Blood Pressure

DOI: $10.18376 /$ jesp/2019/v15/i1/111314

\section{Introduction}

Nowadays cricketers undergo extreme training to be in highest state of physical fitness. Blood pressure is one the most important hemodynamic variable and is often used to identify the fitness 


\section{Journal of Exercise Science \& Physiotherapy Vol. 15 No. 1 (January to June) 2019 ISSN: 0973-2020 (Print) $\quad \mathrm{I}_{2} \mathrm{OR}$ Impact Factor $=6.502 \quad$ ISSN: 2454-6089 (Online)}

level in players (Fagard1993). An optimal blood pressure mostly indicates an extremely fit player. Studies have been revealed that blood pressure has a positive relationship with training (Nandalal and Harmandeep 2015). Cardiac output (CO) is the product of stroke volume (SV) and heart rate (HR) and it represents the body's ability to meet the metabolic demands of exercise; it may increase by five to six fold when an individual is exerting maximal effort during exercise (Warburton et al. 1999a). Maximal heart rate (HR) varies innately among individuals and decreases with age. The increase in heart rate (HR) is responsible for the majority of the augmentation of Cardiac output (CO) during exercise, and peak HR heart rate (HR) is a fundamentally limiting factor of peak exercise capacity in healthy individuals. However, maximal heart rate (HR) does not increase with exercise training; thus, it is not considered to be an adaptable property. In contrast, stroke volume (SV) both at rest and during exercise increases with prolonged exercise training (Baggish 2013). Stroke volume (SV) rises during exercise due to increases in ventricular end-diastolic volume and, to a lesser degree, due to sympathetically mediated reductions in end-systolic volume (Rowell et al. 1986). Cardiac output will continue to increase till the point where a plateau is reached (Adikali et al,. 2017). Activities that involve both aerobic and anaerobic type primarily represent a volume challenge for the heart, which affects all four chambers (Baggish 2013).It has been found that individuals with a high level of physical fitness (athletes) are to have lower heart rates at submaximal workloads, higher maximal oxygen consumptions and quicker drops in the recovery rate than sedentary individuals (Withers and Haslam 1975). Studies have found that recovery heart rates return to near basal levels faster in individuals who are physically fit. The rate of change towards basal levels is also dependent upon the integrity of the cardiovascular system and the health of the individual (Dimkpa 2009). It is generally agreed that training induced bradycardia is a form of adaptation. With this background, we tried to evaluate the effects of exercise on blood pressure and heart rates between trained cricketers given amount of exercise. There are very few studies that have been conducted on male cricket players of Punjab to observe their physiological status haemodynamic variables. The present study was conducted on male cricket players to observe their cardiac output before and after step test according to their playing positions in Punjab, Patiala.

\section{Materials and Methods}

One hundred fifty $(\mathrm{N}=150)$ Punjabi male cricketers between the age group of 15 to 25 years voluntarily participated in the study. Anthropometric measurements were recorded according to the standard procedure. Blood pressure was recorded with a digital sphygmomanometer according to the standardized protocol recommended by World Health Organization. Blood pressure was measured at rest and after the completion of queens step test. The blood pressure in the arteries rises and falls with the phases of the heart beat. The highest pressure in the arteries, produced as a result of ventricular contraction is known as the systolic blood pressure. The lowest pressure in the arteries, produced as a result of ventricular relaxation is known as the diastolic blood pressure (Wayne 2005). The cardiac output was calculated with the help of following standard equations.

Cardiac Output $(\mathrm{ml} / \mathrm{min})=$ Heart Rate $($ beats $/ \mathrm{min}) \times$ Stroke Volume $(\mathrm{ml} /$ beat) $($ Jackson et al., 1955)

\section{Results}

The mean age, height weight and BMI (body mass index) of batsman cricketer was $17.75 \pm 2.88$ year, $171.00 \pm 6.56 \mathrm{~cm}, 57.00 \pm 8.80 \mathrm{~kg}$ and $19.42 \pm 2.22 \mathrm{~kg} / \mathrm{m}^{2}$ respectively. The mean age, height weight and BMI (body mass index) of fast-bowler cricketer was $18.06 \pm 2.43$ year, $172.68 \pm 7.50 \mathrm{~cm}$, $59.16 \pm 8.99 \mathrm{~kg}$ and $19.84 \pm 2.99 \mathrm{~kg} / \mathrm{m}^{2}$ respectively. The mean age, height weight and BMI (body mass index) of spinner cricketer was $17.88 \pm 2.93$ year, $169.40 \pm 8.94 \mathrm{~cm}, 56.32 \pm 10.45 \mathrm{~kg}$ and $19.54 \pm 2.87 \mathrm{~kg} / \mathrm{m}^{2}$ respectively. The mean age, height weight and BMI (body mass index) of batsman/wicketkeeper cricketer was $18.08 \pm 3.47$ year, $172.75 \pm 8.30 \mathrm{~cm}, 58.67 \pm 10.34 \mathrm{~kg}$ and $19.56 \pm 2.47 \mathrm{~kg} / \mathrm{m}^{2}$ respectively. The mean age, height weight and BMI (body mass index) of allrounder cricketer was $17.26 \pm 1.74$ year, $170.81 \pm 7.74 \mathrm{~cm}, 56.89 \pm 10.10 \mathrm{~kg}$ and $19.42 \pm 2.71 \mathrm{~kg} / \mathrm{m}^{2}$ 
Journal of Exercise Science \& Physiotherapy Vol. 15 No. 1 (January to June) 2019

ISSN: 0973-2020 (Print) $\quad \mathrm{I}_{2} \mathrm{OR}$ Impact Factor $=6.502$

ISSN: 2454-6089 (Online)

respectively (Table1).

Table 1. Mean \pm SD of Age, height weight and BMI of Cricket Players

\begin{tabular}{|l|c|c|c|c|c|}
\hline Player's Playing Position & N & $\begin{array}{c}\text { Age, } \\
(\text { year })\end{array}$ & $\begin{array}{c}\text { Height } \\
(\mathrm{cm})\end{array}$ & $\begin{array}{c}\text { Body weight } \\
(\mathrm{kg})\end{array}$ & $\begin{array}{c}\text { BMI } \\
\left(\mathrm{kg} / \mathrm{m}^{2}\right)\end{array}$ \\
\hline Batsman & $\mathbf{5 5}$ & $\mathbf{1 7 . 7 5} \pm 2.88$ & $\mathbf{1 7 1 . 0 0} \pm 6.56$ & $\mathbf{5 7 . 0 0} \pm 8.80$ & $\mathbf{1 9 . 4 2} \pm 2.22$ \\
\hline Fast-bowler & $\mathbf{3 1}$ & $\mathbf{1 8 . 0 6} \pm \mathbf{2 . 4 3}$ & $\mathbf{1 7 2 . 6 8} \pm 7.50$ & $\mathbf{5 9 . 1 6} \pm 8.99$ & $\mathbf{1 9 . 8 4} \pm 2.99$ \\
\hline Spinner & $\mathbf{2 5}$ & $\mathbf{1 7 . 8 8} \pm 2.93$ & $\mathbf{1 6 9 . 4 0} \pm 8.94$ & $\mathbf{5 6 . 3 2} \pm 10.45$ & $\mathbf{1 9 . 5 4} \pm 2.87$ \\
\hline Batsman/Wicketkeeper & $\mathbf{1 0}$ & $\mathbf{1 8 . 0 8} \pm 3.47$ & $\mathbf{1 7 2 . 7 5} \pm 8.30$ & $\mathbf{5 8 . 6 7} \pm 10.34$ & $\mathbf{1 9 . 5 6} \pm 2.47$ \\
\hline All-rounder & $\mathbf{2 9}$ & $\mathbf{1 7 . 2 6} \pm 1.74$ & $\mathbf{1 7 0 . 8 1} \pm 7.74$ & $\mathbf{5 6 . 8 9} \pm 10.10$ & $\mathbf{1 9 . 4 2} \pm 2.71$ \\
\hline Total & $\mathbf{1 5 0}$ & $\mathbf{1 7 . 7 7} \pm 2.66$ & $\mathbf{1 7 1 . 1 9} \pm 7.52$ & $\mathbf{5 7 . 4 5} \pm 9.42$ & $\mathbf{1 9 . 5 4} \pm 2.58$ \\
\hline
\end{tabular}

The mean cardiac output (at rest) of batsman, fast-bowler, spinner, batsman/wicketkeeper, allrounder cricket players was $6.28 \pm 1.08(\mathrm{ml} / \mathrm{min}), 6.06 \pm 0.99(\mathrm{~L} / \mathrm{min}), 6.27 \pm 1.28(\mathrm{~L} / \mathrm{min}), 6.31 \pm 1.48$ $(\mathrm{L} / \mathrm{min})$ and $6.07 \pm 1.01(\mathrm{~L} / \mathrm{min})$ respectively. The maximum mean cardiac output at rest $(6.74$ $\mathrm{L} / \mathrm{min})$ was of Spinner. The minimum cardiac output (at rest) $(6.06 \mathrm{~L} / \mathrm{min})$ was of fast-bowler (Table 2).

Table 2. Comparison of Cardiac output (resting) of Cricket Players according to their Playing Positions

\begin{tabular}{|l|c|c|c|c|c|}
\hline Player's Playing Position & \multicolumn{2}{|c|}{$\begin{array}{c}\text { Cardiac Output } \\
\text { (at rest) }\end{array}$} & \multicolumn{2}{c|}{$\begin{array}{c}\text { Cardiac Output } \\
\text { (after Queen's step test) }\end{array}$} \\
\cline { 2 - 6 } & N & Mean & $\begin{array}{c}\text { Std. } \\
\text { Deviation }\end{array}$ & Mean & $\begin{array}{c}\text { Std. } \\
\text { Deviation }\end{array}$ \\
\hline Batsman & 55 & 6.28 & 1.08 & 10.82 & 1.90 \\
\hline Fast-bowler & 31 & 6.06 & $\mathbf{0 . 9 9}$ & 10.82 & 1.97 \\
\hline Spinner & 25 & 6.74 & 1.28 & 10.97 & 2.38 \\
\hline Batsman/Wicketkeeper & 10 & 6.31 & 1.48 & 11.39 & 1.99 \\
\hline All-rounder & 29 & 6.07 & 1.01 & 11.46 & 1.88 \\
\hline Total & 150 & 6.20 & 1.10 & 11.01 & 2.00 \\
\hline
\end{tabular}

The mean cardiac output (after Queen's step test) of batsman, fast-bowler, spinner, batsman/wicketkeeper and all-rounder cricket players was 10.82 $\pm 1.90(\mathrm{~L} / \mathrm{min}), 10.82 \pm 1.97(\mathrm{~L} / \mathrm{min})$, $10.97 \pm 2.38(\mathrm{~L} / \mathrm{min}), 11.39 \pm 1.99(\mathrm{~L} / \mathrm{min})$ and $11.46 \pm 1.88(\mathrm{~L} / \mathrm{min})$ respectively. The maximum mean cardiac output after step test was of all-rounder. The minimum cardiac output after step test $(10.82 \mathrm{~L} / \mathrm{min})$ was of fast-bowler (Table 2$)$. Thus, the cardiac output was significantly increased substantially, up to 23 percent after step test than at rest of cricket players.

\section{Discussion}

The results of the present study shows that cardiac output (at rest) of the cricket players were in the normal range $(4.0-8.0 \mathrm{~L} / \mathrm{min})$ as per the norms recommended by Edwards's Life Sciences (Edwards, 2009). Rowell (1986) reported that the pattern of blood flow changes dramatically when a person goes from resting to exercising. At rest, the skin and skeletal muscles receive about 20 percent of the cardiac output. During exercise, more blood is sent to the active skeletal muscles and, 


\section{Journal of Exercise Science \& Physiotherapy Vol. 15 No. 1 (January to June) 2019 ISSN: 0973-2020 (Print) I I OR Impact Factor $=6.502 \quad$ ISSN: 2454-6089 (Online)}

as body temperature increases, more blood is sent to the skin. This process is accomplished both by the increase in cardiac output and by the redistribution of blood flow away from areas of low demand, such as the splanchnic organs. This process allows about 80 percent of the cardiac output to go to active skeletal muscles and skin at maximal rates of work. With exercise of longer duration, particularly in a hot and humid environment, progressively more of the cardiac output will be redistributed to the skin to counter the increasing body temperature, thus limiting both the amount going to skeletal muscle and the exercise endurance (Rowell 1986). Cardiac output at rest and during submaximal exercise is essentially unchanged following an endurance training program. At or near maximal rates of work, however, cardiac output is increased substantially, up to 30 percent or more (Saltin and Rowell 1980). At rest and during exercise, myocardial oxygen demand and coronary blood flow are closely linked. This coupling is necessary because the myocardium depends almost completely on aerobic metabolism and therefore requires a constant oxygen supply. Even at rest, the myocardium's oxygen use is high relative to the blood flow. About 70 to 80 percent of the oxygen is extracted from each unit of blood crossing the myocardial capillaries; by comparison, only about 25 percent is extracted from each unit crossing skeletal muscle at rest. In the healthy heart, a linear relationship exists between myocardial oxygen demands, consumption, and coronary blood flow, and adjustments are made on a beat-to-beat basis. The three major determinants of myocardial oxygen consumption are heart rate, myocardial contractility, and wall stress (Marcus 1983; Jorgensen et al. 1977). With exercise of longer duration, particularly in a hot and humid environment, progressively more of the cardiac output will be redistributed to the skin to counter the increasing body temperature, thus limiting both the amount going to skeletal muscle and the exercise endurance (Rowell 1986). Several factors contribute to the increase in stroke volume from endurance training. Endurance training increases plasma volume by approximately the same percentage that it increases stroke volume (Green, Jones, Painter 1990). An increased plasma volume increases the volume of blood available to return to the right heart and, subsequently, to the left ventricle. There is also an increase in the end diastolic volume (the volume of blood in the heart at the end of the diastolic filling period) because of increased amount of blood and increased return of blood to the ventricle during exercise (Seals et al. 1994). The cardiovascular and respiratory responses to episodes of resistance exercise are mostly similar to those associated with endurance exercise. One notable exception is the exaggerated blood pressure response that occurs during resistance exercise. Part of this response can be explained by the fact that resistance exercise usually involves muscle mass that develops considerable force. Such high, isolated force leads to compression of the smaller arteries and results in substantial increases in total peripheral resistance (Coyle 1991).

\section{Conclusion}

It was concluded that the cardiac output was significantly increased substantially, up to 23 percent after step test than at rest of cricket players. The maximum mean cardiac output at rest was of Spinner. After step test, the maximum mean cardiac output was of all-rounder. The trained cricketers were able to increase their SBP with relatively lower heart rates, which may probably be due to their increase in stroke volume. Cricketers had much lower resting heart rates and their heart rates reached to basal levels more quickly showing more fitness than normal non athletic people. The diastolic response between the resting and after queens step test did not differ much although it shows changes in DBP were similar to SBP on a smaller scale. This shows that regular training has beneficial effect on body by making it better at adapting to situations of demand like exercise. It was also seen that all rounder's had the highest cardiac output when compared to other players shown the highest degree of adaption as they are required to perform at their optimal best at all times. 


\section{Journal of Exercise Science \& Physiotherapy Vol. 15 No. 1 (January to June) 2019 \\ ISSN: 0973-2020 (Print) I I OR Impact Factor =6.502 ISSN: 2454-6089 (Online)}

\section{Acknowledgment}

The authors thank all the subjects who voluntarily participated in this study from Govt. Multi-Purpose Secondary School Patiala, Cricket Hub Academy Patiala, Master Cricket Class Academy Patiala, Budda Dal Sports Complex Patiala, DMW Cricket Academy Patiala and Black Elephant Cricket Club Patiala and all other Cricket Academies situated at Patiala, Punjab.

\section{References}

Adikali Kaba Sesay 1, Alpha Bassie Mansaray' Javed Soomro Ali (2017). Exercise and Its Corresponding Effect on Cardiac Output. International Journal of Scientific and Research Publications, pp 546555.

Baggish Al ( 2013). The athlete's heart. In: Cardiac Adaptation. Advances in Biochemistry in Health and Disease. Ostadal B, Dhalla Ns (eds), Springer Science and Business Media, pp 289-302.

Dimkpa, U (2009). Post Exercise Heart Rate Recovery an index of cardiovascular fitness. Journal of Exercise Physiology. 12(1): 10-23.

Edward lifesciences LLC (2009). www.edwards.com

Fagard R.H. (1996).Athlete's heart: a meta-analysis of the echocardiographic experience. Int J Sports Med. Nov; 17 Suppl 3:S140-4.

Jackson, C. E. (1955). Nomogram for simple calculation of cardiac output. Circulation 11: 635.

Jorgensen CR, Gobel FL, Taylor HL, Wang Y(1977). Myocardial blood flow and oxygen consumption during exercise. Annals of the New York Academy of Sciences; 301: 213-223.

Marcus ML(1983). The coronary circulation in health and disease. New York: McGraw Hill,

Nandalal Singh and Harmandeep Kaur (2015). Pulse rate and blood pressure among selected non-contact games: A comparative study. International Journal of Multidisciplinary Research and Development Online ISSN: 2349-4182 Print ISSN: 2349-5979, Volume 2; Issue 11; November 2015; Page No. 166-168.

Rowell LB (1986). Human circulation regulation during physical stress. New York: Oxford University Press.

Rowell LB (1993). Human cardiovascular control. New York: Oxford University Press.

Saltin B, Rowell LB(1980). Functional adaptations to physical activity and inactivity. Federation Proceedings. Vol. 39: 1506-1513.

Warburton De, Haykowsky Mj, Quinney Ha, Humen Dp, Teo Kk (1999c). Reliability and validity of measures of cardiac output during incremental to maximal aerobic exercise. Part II: Novel techniques and new advances. Sports Med 27: 241-260.

Wayne (2005). Austin Community College.Indirect Measurement of Arterial Blood Pressure Cardiovascular Index, Mammalian Diving Reflex.

Withers, RT and Haslam, RW (1975). Heart Rates at sub-maximal relative workloads in subjects of high and medium fitness. Br J Sports Med; 9(4) 187-90.

Conflict of Interest: None declared 